\title{
Correlating Dynamics and Selectivity in Adsorption of Semiconductor Nanocrystals onto a Self-organized
}

\author{
Pattern
}

Xiaodong Chen, Michael Hirtz, Andrey L. Rogach, Dmitri V. Talapin, Harald Fuchs, and Lifeng Chi

\section{Experimental Section}

Materials: DPPC (L- $\alpha$-dipalmitoyl-phosphatidylcholine, > 99\%) was purchased from Fluka and used without further purification; BODIPY (2-(4,4-difluoro-5-methyl-4-bora-3a,4a-diaza-s-indacene-3dodecanoyl)-1-hexadecanoyl-sn-glycero-3-phosphocholine) was purchased from Molecular Probes (Leiden, the Netherlands). These two phospholipids were dissolved in chloroform (HPLC grade) purchased from AppliChem (Darmstadt, Germany). The non-polar test liquids (hexadecane, decane, octane) and the phenyloctane were purchased from Sigma Aldrich, purity was $>95 \%$ or better. Water was taken from a Millipore pure water system $(18.2 \mathrm{M} \Omega \cdot \mathrm{cm})$. CdSe NCs used in this work were synthesized according to the previously published procedure (Talapin, D. V.; Rogach, A. L.; Kornowski, A.; Haase, M.; Weller, H. Nano Lett. 2001, 1, 207) in a three-component coordinating solvent mixture of hexadecylamine, trioctylphosphine, and trioctylphosphine oxide.

Self-organized Pattern Formation: Luminescent DPPC-based patterns on mica substrates were prepared as described elsewhere. (Chen, X. D.; Hirtz, M.; Fuchs, H.; Chi, L. F. Advanced Materials 2005, 17, 2881-2885.) 
Measurements: AFM measurements were carried out with commercial AFM instruments (Digital Instruments, Nanoscope IIIa, Dimension 3000, Santa Barbara, CA) running in tapping mode. Si cantilevers (Nanosensors) of spring constants 250 - $350 \mathrm{kHz}$ were used. Confocal images were acquired with commercial confocal laser scanning microscope (Leica TCS SL, Heidelberg, Germany), equipped with a $63 \times$ oil immersion objective with a numerical aperture of 1.32 and Ar-laser excitation. Confocal images were obtained at $488 \mathrm{~nm}$ excitation, with emission at 500-550 nm for BODIPY and 650-700 nm for CdSe NCs. Fluorescence spectra were measured with a fluorescence spectrometer (ISA Jobin YvonSPEX FL3-22). Contact angle measurements were carried out on a Contact Angle Measuring System G2 (Krüss, Germany) using sessile drop method. The values reported are averages of at least three measurements made on different areas of the sample surface.

Image analysis: A self-developed program, written in the Visual Studio developing environment, was used to analyze the acquired AFM images. The program detects the different height levels within an AFM image and calculates the coverage accordingly. 
2. Calculating the area of the holes in the channel and in the stripe to determine the rate constant.

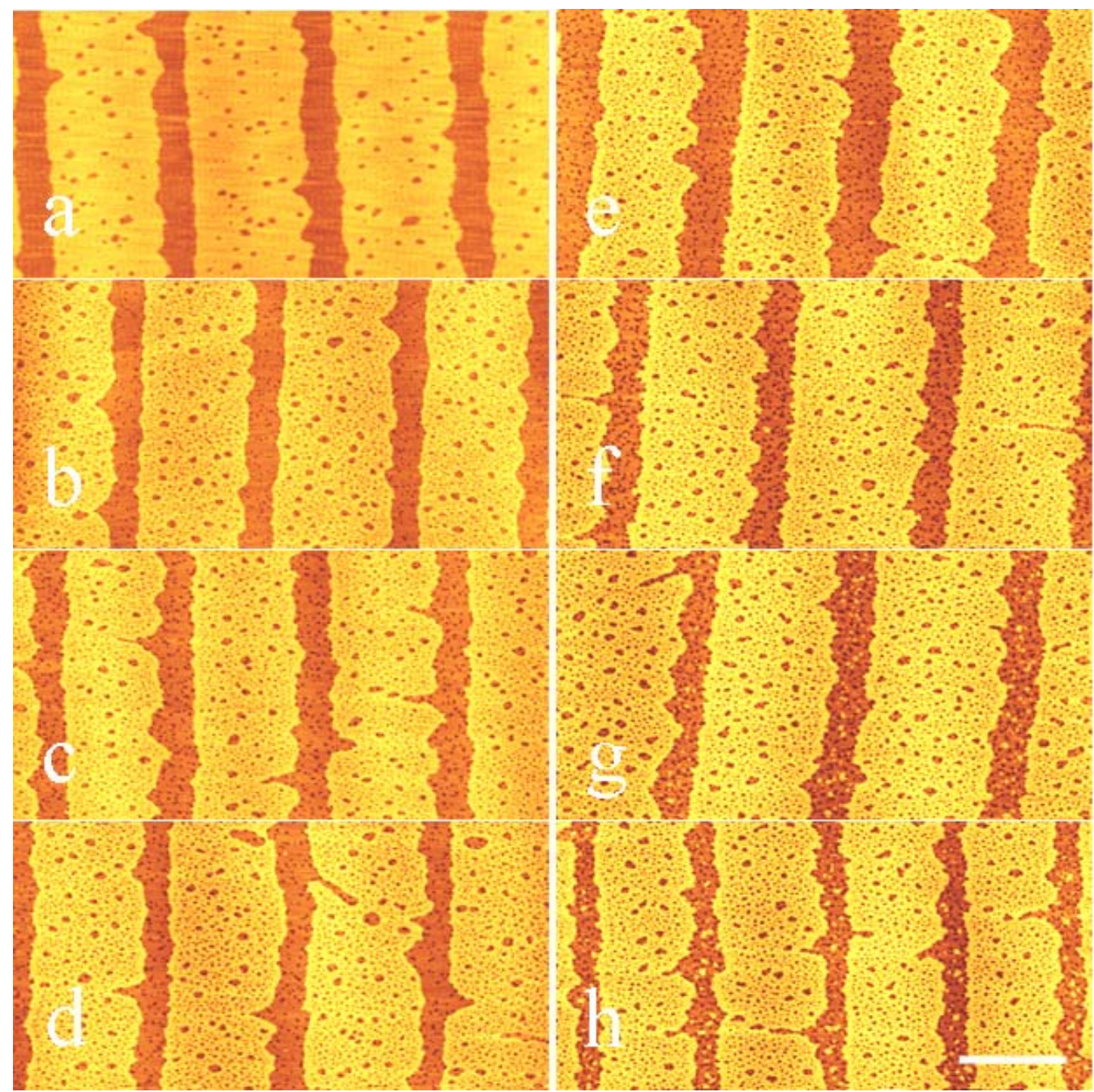

Figure S1. A series of AFM images for phenyloctane on pure DPPC pattern depending on the wetting time. (a) $0 \mathrm{~min}$, (b) $0.5 \mathrm{~min}$, (c) $1 \mathrm{~min}$, (d) $2 \mathrm{~min}$, (e) $5 \mathrm{~min}$, (f) $10 \mathrm{~min}$, (g) $20 \mathrm{~min}$, and (h) $40 \mathrm{~min}$. $($ Scale bar $=1 \mu \mathrm{m})$

Table S1. Parameters obtained by fitting the coverage depending on wetting time to the monoexponential equation.

\begin{tabular}{cccccc}
\hline Coverage & $\mathrm{A}$ & $\begin{array}{c}\tau \\
\mathrm{k}=1 / \tau\left(\mathrm{s}^{-1}\right)\end{array}$ & $\mathrm{C}_{0}$ & $\mathrm{r}^{2}$ \\
& & & & \\
\hline Mica in channel & $0.133 \pm 0.006$ & $55 \pm 4$ & $0.018 \pm 0.002$ & $0.113 \pm 0.004$ & 0.89537 \\
Expanded DPPC & $0.089 \pm 0.006$ & $89 \pm 15$ & $0.011 \pm 0.002$ & $0.139 \pm 0.002$ & 0.9935 \\
in stripe & & & & & 0.98201 \\
Mica in stripe & $0.025 \pm 0.002$ & $440 \pm 126$ & $0.0023 \pm 0.0006$ & $0.026 \pm 0.002$ & 0.002 \\
\hline
\end{tabular}




\section{Calculation of interfacial energy, the adhesion energy, and work of adhesion based on contact angle measurement.}

The contact angle measurements where conducted on samples freshly prepared as follows: condensed DPPC monolayer samples were obtained by LB transfer of a DPPC monolayer at the airwater interface onto freshly cleaved mica with a transfer speed of $5 \mathrm{~mm} / \mathrm{min}$ and a lateral pressure of 30 $\mathrm{mN} / \mathrm{m}$. The expanded DPPC monolayer samples were obtained by transferring a DPPC monolayer at the air-water interface with $600 \mathrm{~mm} / \mathrm{min}$ at a lateral pressure of $3 \mathrm{mN} / \mathrm{m}$. After the transfer the contact angles of three non-polar (hexadecane, decane, octane) and two polar (water, phenyloctane) test liquids were measured. Although one non-polar and one polar test liquid would have been sufficient for the determination of surface energies, we choose to take additional test liquids to ensure validity of measurements. Surface energies were calculated from the contact angles by the combined method of Fowkesx, Owens and Wendt (Fowkes, F. M. Industrial and Engineering Chemistry 1964, 56, 40-52 / Owens, D. K.; Wendt, R. C. Journal of Applied Polymer Science 1969, 13, 1741-1747). The measured contact angles are shown in table S2, the resulting surface energies for condensed and expanded DPPC phase and the surface energy of naked mica for comparison are shown in table S3.

Table S2: Surface energy components of probed liquids and contact angles on condensed and expanded DPPC phase by the liquid.

\begin{tabular}{cccccc}
\hline Test Liquid & \multicolumn{2}{c}{ Surface energy component $(\mathrm{mN} / \mathrm{m})$} & \multicolumn{2}{c}{ Contact Angle $\left( \pm 1^{\circ}\right)$} \\
\cline { 2 - 6 } & $\gamma_{1}$ & $\gamma_{1}^{\mathrm{d}}$ & $\gamma_{1}^{\mathrm{p}}$ & $\begin{array}{c}\text { Condensed } \\
\text { Phase }\end{array}$ & $\begin{array}{c}\text { Expanded } \\
\text { Phase }\end{array}$ \\
\hline Hexadecane & 27.6 & 27.6 & 0 & $42^{\circ}$ & $30^{\circ}$ \\
Decane & 23.9 & 23.9 & 0 & $26^{\circ}$ & $\left(0^{\circ}\right)$ \\
Octane & 21.8 & 21.8 & 0 & $14^{\circ}$ & $\left(0^{\circ}\right)$ \\
Water & 72.6 & 18.7 & 54.1 & $99^{\circ}$ & $72^{\circ}$ \\
1-Phenyloctane & 31.8 & 29.8 & 2 & $46^{\circ}$ & $18^{\circ}$ \\
\hline
\end{tabular}


Table S3: Dispersive part $\gamma^{D}$, polar part $\gamma^{P}$ and total surface energy $\gamma$ of condensed DPPC phase, expanded DPPC phase, and mica.

\begin{tabular}{lccc}
\hline & $\gamma^{\mathrm{D}}$ & $\gamma^{\mathrm{P}}$ & $\gamma$ \\
\hline Condensed Phase & $21.2 \mathrm{mN} / \mathrm{m}$ & $2.2 \mathrm{mN} / \mathrm{m}$ & $23.4 \mathrm{mN} / \mathrm{m}$ \\
Expanded Phase & $24.1 \mathrm{mN} / \mathrm{m}$ & $13.0 \mathrm{mN} / \mathrm{m}$ & $37.1 \mathrm{mN} / \mathrm{m}$ \\
Mica $^{*}$ & $30 \mathrm{mN} / \mathrm{m}$ & $90 \mathrm{mN} / \mathrm{m}$ & $120 \mathrm{mN} / \mathrm{m}$
\end{tabular}

* From Schultz, J.; Tsutsumi, K.; Donnet, J. B. Journal of Colloid and Interface Science 1977, 59, 277 282.

\section{Appendix: Calculation of interfacial energy from contact angles}

By combining Fowkes equation for the dispersive part of interaction

$$
\gamma_{s l} \approx \gamma_{s}+\gamma_{l}-2 \sqrt{\gamma_{s}^{D} \cdot \gamma_{l}^{D}}
$$

with the Young's equation

$$
\gamma_{\mathrm{s}}=\gamma_{\mathrm{sl}}+\gamma_{1} \cdot \cos (\theta)
$$

an expression in a form similar to a straight line can be obtained (for non-polar liquids $\gamma_{1}=\gamma_{1}^{\mathrm{D}}$ ):

$$
\cos (\theta)=2 \sqrt{\gamma_{s}^{D}} \cdot \frac{1}{\sqrt{\gamma_{l}^{D}}}-1
$$

The dispersive part of the surface energy $\gamma_{s}^{\mathrm{D}}$ can be determined by measuring the contact angle of nonpolar liquids of known $\gamma_{1}^{\mathrm{D}}$ and plotting the cosine of measured contact angles against $1 / \sqrt{\gamma_{1}^{\mathrm{D}}}$. The slope of the resulting straight line (with intersection at -1 ) equals $2 \sqrt{\gamma_{s}^{\mathrm{D}}}$.

Once $\gamma_{s}^{D}$ is known, $\gamma_{s}^{\mathrm{P}}$ can be obtained as follows: Fowkes' equation is extended by the polar interactions:

$$
\gamma_{s l}=\gamma_{s}+\gamma_{l}-2\left(\sqrt{\gamma_{s}^{D} \cdot \gamma_{l}^{D}}+\sqrt{\gamma_{s}^{P} \cdot \gamma_{l}^{P}}\right)
$$

Further it's assumed that the work of adhesion can be written as a sum of polar and non-polar part:

$$
\mathrm{W}_{\mathrm{sl}}=\mathrm{W}_{\mathrm{sl}}^{\mathrm{D}}+\mathrm{W}_{\mathrm{sl}}^{\mathrm{P}}
$$

By adding Young's equation (2) with the equation of Dupré 


$$
\mathrm{W}_{\mathrm{sl}}=\gamma_{\mathrm{s}}+\gamma_{\mathrm{l}}-\gamma_{\mathrm{sl}}
$$

the following expression for $W_{s l}$ is obtained:

$$
W_{s l}=\gamma_{l} \cdot(\cos (\theta)+1)
$$

By combining (4),(5) and (7) $\mathrm{W}_{\mathrm{sl}}^{\mathrm{P}}$ can be written as

$$
\mathrm{W}_{\mathrm{sl}}^{\mathrm{P}}=\gamma_{\mathrm{I}} \cdot(\cos (\theta)+1)-2 \sqrt{\gamma_{\mathrm{s}}^{\mathrm{D}} \cdot \gamma_{\mathrm{I}}^{\mathrm{D}}}
$$

According to (4) $\mathrm{W}_{\mathrm{sl}}^{\mathrm{P}}$ can also be written as

$$
W_{s l}^{P}=2 \sqrt{\gamma_{s}^{P} \cdot \gamma_{l}^{P}}
$$

Thus by measuring the contact angle of a polar liquid of known $\gamma_{1}^{P}$ and $\gamma_{1}^{D}$ and knowing $\gamma_{s}^{D}$ one can calculate $W_{s l}^{P}$ by equation (8). According to equation (9) plotting $W_{s l}^{P}$ against $2 \sqrt{\gamma_{l}^{P}}$ yields a straight line through the origin. The wanted $\gamma_{s}^{\mathrm{P}}$ can be obtained by the slope of this line that equals $\sqrt{\gamma_{s}^{\mathrm{P}}}$.

According to equation (4), we have estimated the interfacial energies of the different interfaces: $\gamma_{\mathrm{NC} \text {-phenyloctane }}=1.9 \mathrm{~mJ} / \mathrm{m}^{2}, \gamma_{\mathrm{NC} \text { - condensed }}=1.1 \mathrm{~mJ} / \mathrm{m}^{2}, \gamma_{\text {condensed-phenyloctane }}=0.7 \mathrm{~mJ} / \mathrm{m}^{2}, \gamma_{\mathrm{NC} \text {-expanded }}=1.3$ $\mathrm{mJ} / \mathrm{m}^{2}, \gamma_{\text {expanded-phenyloctane }}=5.0 \mathrm{~mJ} / \mathrm{m}^{2}, \gamma_{\text {NC-mica }}=49.4 \mathrm{~mJ} / \mathrm{m}^{2}$, and $\gamma_{\text {mica-phenyloctane }}=65.0 \mathrm{~mJ} / \mathrm{m}^{2}$. Here, we used the surface energy of octanol $\left(27.6 \mathrm{~mJ} / \mathrm{m}^{2}\right.$ with $\gamma^{\mathrm{d}}$ of 21.3 and $\gamma^{\mathrm{p}}$ of $\left.6.3 \mathrm{~mJ} / \mathrm{m}^{2}\right)(\mathrm{J}$. Colloid and Interface Science $1977,59,277)$ to estimate the surface energy of NCs because of the similar length to TOPO. Finally, the adhesion energy between NC and substrate is calculated by $E_{a d}=A_{e f f}\left(\gamma_{13}-\gamma_{12}-\gamma_{23)}: \mathrm{E}_{\mathrm{ad}(\mathrm{NC}-\text { condensed })}=-5.2 \times 10^{-19} \mathrm{~J}, \mathrm{E}_{\mathrm{ad}(\mathrm{NC}-\text { expanded })}=-1.9 \times 10^{-18} \mathrm{~J}\right.$, and $\mathrm{E}_{\mathrm{ad}(\mathrm{NC}-\mathrm{mica})}=$ $-6.0 \times 10^{-18} \mathrm{~J}$

The work of adhesion of the liquid to the solid is calculated based on equation (7). The static contact angle of 1-phenyloctane on mica is $8^{\circ}$. Then, the work of adhesion of 1-phenyloctane on expanded DPPC, condensed DPPC, and mica is $62.0 \mathrm{~mJ} / \mathrm{m}^{2}, 53.7 \mathrm{~mJ} / \mathrm{m}^{2}$, and $63.3 \mathrm{~mJ} / \mathrm{m}^{2}$, respectively. 


\section{The selective adsorption of CdSe nanocrystals on the DPPC pattern with different sizes}

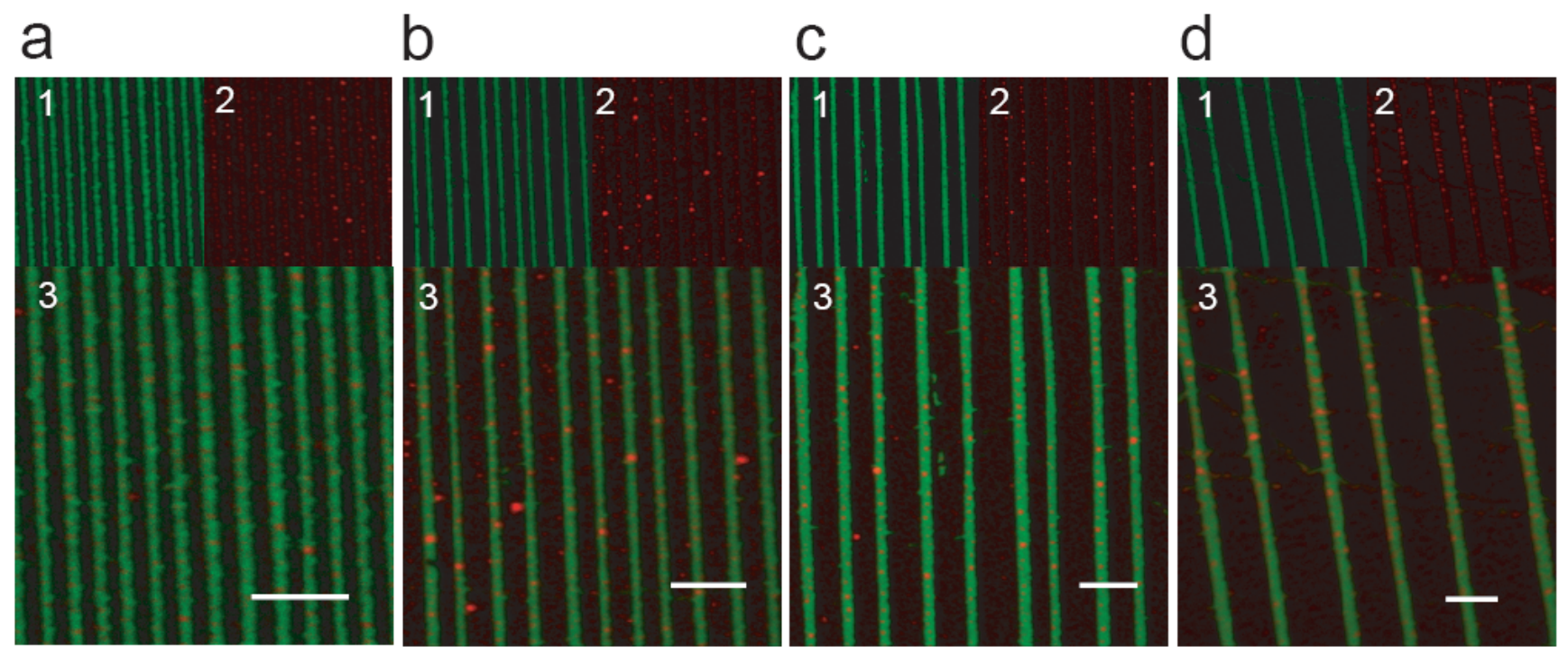

Figure S2. Selective adsorption of CdSe nanocrystals on DPPC/BODIPY patterned substrate (5 min wetting) prepared by different conditions. (a) $60 \mathrm{~mm} / \mathrm{min}$ and $2 \mathrm{mN} / \mathrm{m}$, (b) $20 \mathrm{~mm} / \mathrm{min}$ and $2 \mathrm{mN} / \mathrm{m}$, (c) $10 \mathrm{~mm} / \mathrm{min}$ and $2 \mathrm{mN} / \mathrm{m}$, and (d) $5 \mathrm{~mm} / \mathrm{min}$ and $2 \mathrm{mN} / \mathrm{m}$. (1) CLSM image for BODIPY luminescent stripe patterns $(\lambda \mathrm{ex}=488 \mathrm{~nm}$, detection range $500-550 \mathrm{~nm})$. (2) CLSM image for CdSe NCs arrays ( $\lambda$ ex $=488 \mathrm{~nm}$, detection range $650-700 \mathrm{~nm}$ ). (3) Merged image of images of 1 and 2. (Scale bar $=4 \mu \mathrm{m})$ 